\title{
Policies with Varying Costs and Benefits: A Land Conservation Classroom Game
}

\author{
Sahan T. M. Dissanayake ${ }^{1}$ and Sarah A. Jacobson ${ }^{2}$
}

December 2015

\begin{abstract}
: (limit: 125 words)
Some policies try to maximize net benefits by targeting different individuals to participate. This is difficult when costs and benefits of participation vary independently, as they do in land conservation. We share a classroom game that explores cases in which minimizing costs may not maximize benefits and vice versa. This game is a contextually rich pedagogical tool, putting students in the role of landowners who must decide whether to conserve land in different policy environments: flat conservation payments, agglomeration bonuses, and a conservation auction. Students learn about specific issues in land conservation, ecosystem services, preferences for non-money outcomes, and general issues in policymaking. The game is suited to classes in environmental, resource, agricultural, and policy economics, and more general classes in microeconomics and public policy.
\end{abstract}

Keywords: classroom game, spatial agglomeration, conservation, land use, economic education JEL Codes: A22, Q24, Q57

\footnotetext{
${ }^{1}$ Assistant Professor, Department of Economics, Colby College, Diamond 347, 5247 Mayflower Hill, Waterville, ME, 04901-8852, 207-859-5241, sdissan2@gmail.com, http://sahan.org/

${ }^{2}$ Corresponding author. Assistant Professor, Department of Economics, Williams College, 24 Hopkins Hall Drive, Williamstown, MA, 01267, 413-597-4766, sarah.a.jacobson@williams.edu, http://econ.williams.edu/people/saj2. Feedback on the game is welcome, so please let us know how it works for you!
} 


\section{Introduction}

In this paper, we share a classroom game that can help students learn about policymaking contexts in which costs and benefits vary independently. This is a public goods game played in a land conservation setting. It is ideally suited to classes in environmental, agricultural, and natural resource economics at any level, but can also fit well in classes on public economics and public policy and in policy-oriented microeconomics classes. The game can be completed in a single 50 or 75 minute class period, and works best in a class of size 16-60 students.

In this game, students take the role of landowners deciding whether to conserve their plots of land given different government policies to incentivize conservation. The policies try to either maximize benefits or minimize costs of conservation, and both costs and benefits vary idiosyncratically across the plots of land. In our experience, students often don't grasp how incentive schemes work until they have tried to make their own optimizing decisions facing those incentives. They may also find it difficult to think separately about costs and benefits in these contexts and in general, especially when some of the costs and benefits (e.g. opportunity costs and ecosystem service benefits) seem abstract. This game overcomes these challenges by creating a learning environment that engages students in solving a real-world problem in which policy-makers must consider independent costs and benefits. The game has the following learning outcomes:

1. Familiarity with specific policies that can be used to conserve land.

2. A practical understanding of the importance of incentives with regard to land conservation (and economics broadly).

3. An understanding of the importance of ecosystem services and how those ecosystem services may depend on the spatial configuration of conserved land.

4. An understanding of how policy design can minimize social costs (e.g. opportunity costs of enrollment) and how it can maximize social benefits (e.g. ecosystem services).

5. A sense of the tradeoffs that policymakers face when costs and benefits vary independently from each other.

6. Insights into non-money preferences that may drive behavior (e.g. social preferences or preferences for conservation).

7. Experience making decisions in a strategic setting.

The contextual richness of this game adds realism that brings policy issues to life in the classroom and showcases the complexities of the tradeoffs policymakers must make when they seek socially optimal outcomes. The game is flexible in that the treatments we offer can be "mixed and matched" and repeated as desired and additional treatments can be added or substituted to fine tune the game to your course. We suggest ways in which the context of the game can be modified to address other land use configurations, or even to explore social policies that target individual education or poverty. 
We have played the game in three environmental and resource economics classes at two liberal arts schools in the northeastern US in Spring 2014 and Spring 2015. Students respond strongly to economic incentives but also voluntarily "conserve" if the cost of so doing is low enough. The feedback from our students shows that the game helped students engage with the material, understand how people behave under the incentives provided by these policies, and internalize and remember the lessons associated with the exercise.

We proceed as follows. First, we give background information on issues in land conservation that may be useful for instructors or students. Next, we describe the classroom game, also suggesting relevant literature that may be used as readings for the class. We then provide ideas for leading post-experiment discussions. We conclude with our students' reflections on the game and some ideas for modifications that can allow the game to represent other scenarios of interest. In the appendices, we provide instructions and recording sheets, a bullet-point guide to running the game for instructors, and a handout that can be distributed to students to give background on the resource economics concepts that underlie the game.

\section{Land Conservation}

Over the last few centuries, human activities such as farming, deforestation, and urban and suburban expansion have converted tremendous amounts of land worldwide to human-dominated landscapes. As a result, only about fifty percent of the forest area that existed at the time of the rise of agriculture remains as forests today (Millennium Ecosystem Assessment, 2005), 70\% of remaining forest is within $1 \mathrm{~km}$ of the forest's edge (Haddad et al., 2015), and species extinction rates have increased over one hundred-fold due to human activity (Millennium Ecosystem Assessment, 2005). However, undeveloped land provides a host of public goods. When land is conserved (instead of being farmed or developed), erosion is reduced; this preserves soil quality and reduces runoff, thus improving water quality. Conserved land can yield climate benefits through carbon sequestration. Land that is not developed also provides habitat for wildlife, including species that provide direct and indirect benefits to humans. The suite of benefits provided by conserved land is known as “ecosystem services” (Sukhdev et al., 2010).

Because many of these benefits are public goods, land is under-conserved relative to the social optimum, and there is a role for public policy to improve social welfare by increasing land conservation. In the last few decades, policymakers, environmental organizations, and the general public have become more aware of the value of these ecosystem services and are responding by protecting and conserving land.

Which land should be preserved? Not all land yields the same net social benefits. On the one hand, different land has different costs of conservation. These costs are typically opportunity costs: the benefits that could be obtained if the land wasn't conserved, e.g. the land's return to farming. On the other hand, different land may also provide different benefits when conserved. For example, land bordering a waterway may inherently have more potential to provide 
ecosystem services. At the same time, the benefits of conserved land may also depend on the spatial layout of the protected land: large blocks of protected land, or distinct clusters of protected land connected by corridors through which species can travel, will usually provide greater conservation benefits than tiny patches of disconnected conserved land (Dissanayake et al., 2012; Haddad et al., 2015; Parkhurst and Shogren, 2007). Conservation corridors can also provide resiliency for species survival and ecosystem stability against climate-change-induced habitat change (Ando and Mallory, 2012; Conrad et al., 2012; Önal and Briers, 2006; Pressey et al., 2007).

Policymakers' tools for land conservation tend to consider either the varying costs or the benefits of conservation, or neither, but generally not both. Initial land conservation policy focused on maximizing ecological benefits (Dobson et al., 1997), but this can lead to economically inefficient allocation of resources because it ignores costs. Subsequent work has emphasized the importance of incorporating costs into land conservation decisions (Ando et al., 1998; Messer, 2006). A separate set of policies has been studied to target spatially varying benefits of conservation. Agglomeration bonuses can incentivize larger blocks of conserved land and conservation corridors (Parkhurst and Shogren, 2007).

Policies that minimize costs of conservation need not maximize benefits of conservation and vice versa. Policymakers must therefore make tradeoffs between these costs and benefits. This is difficult to do since, while the costs are often denominated in dollars, the benefits are often nonmarket goods that bear no dollar price tag. The complexity of this set of issues is inherently interesting since land conservation is an important resource policy issue; but it also throws central concepts in cost benefit analysis into stark relief.

\section{The Game}

Students in the game play the role of landowners. In each round, each student must decide whether to farm or conserve her land. Farming generates a private return for the landowner. Agricultural returns (and thus the opportunity cost of conservation) vary randomly among the plots. Conservation provides ecosystem service benefits that act as a public good. Conservation benefits depend on the spatial configuration of conserved land. The instructor (as the policymaker) announces a conservation payment scheme in each round. The purpose of the game is to demonstrate how these incentive schemes work and how agents react to them. In this section, we describe the game in detail; supplementary material in the appendix gives step by step instructions and provides materials for the instructor.

The game transforms the classroom into a landscape. The decision-making unit is a plot of land. Each student can play an individual landowner, or in a larger class students can work in pairs or teams to represent an individual landowner. The way students are seated in the classroom 
represents the geographical arrangement of their plots of land. ${ }^{3}$ Each round of the experiment is a conservation contract period, and each is played in a particular policy environment. Each period is independent from the other periods, and each lasts 10 years (the length of most contracts in the US Conservation Reserve Program).

Each student has "earnings" from each round of the game, and these earnings depend on her choices and the choices other students make. The decision each student makes in each round is whether to farm or conserve her plot of land. Each student has a randomly-assigned agricultural quality value that determines her potential income from farming; if she chooses to conserve instead of farming, the current conservation policy determines her income from conservation. Additionally, each student benefits from the total ecosystem services provided by the landscape. These are public good benefits that are received by every student. We quantify these benefits as monetary values and add them to each student's earnings. Each student's total earnings for a conservation period are:

\section{Earnings = Farming Income + Conservation Payments + Ecosystem Services}

The fundamental question the game asks is: how are conservation decisions affected by different policy environments?

Students calculate their earnings in each round and their total earnings for the game. We recommend that decisions be incentivized by paying one or several randomly-selected students their earnings for one randomly-chosen round in cash. This heightens attention and helps students feel the consequences of the tradeoffs. (For a discussion of the use of incentives in classroom experiments, see Holt, 1999.) We suggest alternatives to cash payments below.

In addition to monetary earnings, each round has another outcome: the survival of charismatic megafauna. This animal stock will only endure if a corridor of land that connects the two short edges of the classroom is conserved. This simulates a species' need to migrate or the benefits of linking two different populations with each other. The creation of a corridor provides some ecosystem services (contributing to everyone’s earnings), but students may also get nonmonetary benefits from seeing the megafauna survive.

In the next section, we describe how the game is conducted. We then explain how ecosystem services are calculated, and then we describe each treatment in detail.

\section{Setup and General Conduct}

We suggest you plan for the game to take a single 75-minute class period or one 50-minute period plus some time during the following class for discussion. However, you could cut

\footnotetext{
${ }^{3}$ If the classroom shape is uncongenial to the game (if it is not a rectangle or it is unusually long and thin on one dimension), plot locations can be randomly assigned by handing out index cards with the locations (A1, A2, ..) written on them. This random plot location assignment can also be done in a normal-shaped room if you want to make it more difficult for students (who typically sit near friends) to "collude" to create blocks of conserved land.
} 
treatments and relegate discussion to outside-of-class media to make it take as little as 35 minutes, or you could plan detailed in-class work for before and after the game so that the whole lesson takes as much as three class periods. In this section we describe the game conduct in detail, but Appendix II gives a bullet-point instructor’s guide to running the game.

Send the instructions and recording sheet (Appendix I) to students in advance and ask them to read both before class. You can modify the instructions and the game to suit your needs and interests. In particular, you may change the geographic region and the charismatic megafauna described in the instructions to tell a story closer to home for your students.

You might ask students to read about land conservation before the session. Their textbook may have useful resources. You may want to assign academic papers on land conservation (Ando et al., 1998; Polasky et al., 2008), ${ }^{4}$ conservation auctions (Feather et al., 1999; Polasky et al., 2014), spatial agglomeration (Parkhurst and Shogren, 2007), or recreation benefits from conservation (Sullivan et al., 2004). Recent journalistic articles or blog posts about issues in land conservation in the local area or in the national spotlight can help students connect with the subject. For schools that emphasize connections to the local area, you can provide links to local conservation groups. If students have not yet learned environmental economics basics, you can distribute the handout we provide in Appendix III that explains basic concepts in externalities and public goods in general and specific issues in the context of land conservation and ecosystem services.

During the game, we use an Excel spreadsheet projected at the front of the room to record decisions and calculate earnings. Earnings calculations are complicated because the value of ecosystem services is complex (as discussed in the next section), so a tool like our spreadsheet is essential to render in-class play smooth and straightforward. ${ }^{5}$ The spreadsheet also provides nice visuals of the classroom "landscape" and allows students to study the decision data on their own when you share it after the game is complete.

Before the class in which you run the game, you must prepare the spreadsheet for your needs. You may need to change the shape and size of the landscape to reflect the shape of your classroom, or you may need to add worksheets based on how many rounds you plan to run and of what treatments. Depending on the time available and your interests, you can choose any set of the treatments we describe below. The border and corridor treatments emphasize the spatial

\footnotetext{
${ }^{4}$ The production possibilities frontier (PPF) depicted in Figure 3 of Polasky et al. (2008) is something to emphasize to the students: although there is a tradeoff between protecting more species and economic returns, public goods problems or other sources of inefficiency cause the economy to sit inside the PPF.

${ }^{5}$ If Excel is set to not automatically perform calculations, the spreadsheet will not work! You can find this setting: On a PC:

- 2003: Tools $>$ Options $>$ Calculation $>$ Calculation $>$ Automatic.

- 2007: Office button > Excel options $>$ Formulas > Workbook Calculation > Automatic.

- 2010 and 2013: File > Options > Formulas > Workbook Calculation > Automatic.

On a Mac:

- 2008: Excel Preferences > Calculation > Automatically.
} 
dependence of benefits of conservation, as experimentally explored by Parkhurst and Shogren (2007) and illustrated with regard to forest fragmentation by Haddad et al. (2015). The auction treatment emphasizes the costs of conservation.

The larger (and more talkative) your class, the longer each round will take. For the simpler treatments, a single round is generally sufficient and repetition adds little value; but for complex treatments (particularly the border and corridor), it's helpful to run two rounds within each of which you disallow communication and to allow students to talk freely with each other for five minutes between the rounds. We therefore recommend playing the following set of treatments if time allows: round 1: flat payments; rounds $2 \& 3$ : border bonus; rounds $4 \& 5$ : corridor bonus; and round 6: auction. We recommend that students not be allowed to talk during each round, but that they be given five minutes to talk between rounds 2 and 3 and again between rounds 4 and 5 . The spreadsheet we provide is configured with this set of treatments by default; additional worksheet copies can be made, and undesired worksheets can simply be ignored.

In our experience, a 30-40 student class can complete an abbreviated 3-round version of the experiment in 35 minutes if the group is chatty, or can just squeeze in a full 6-round version (for a less chatty group) in 50 minutes. A 75-minute class allows for playing the full 6-round version followed by a debriefing and discussion.

Before class, you should print pictures (cartoon images work well) of the charismatic megafauna the students can "save" with corridor conservation, one showing the animal alive and the other showing it dead. For example, we use pictures of Bullwinkle Moose.

At the beginning of the class session, give each student a copy of the instructions and recording sheet and a randomly-chosen "farming value" from one to ten. We use a deck of playing cards (ace through ten, with face cards removed) for these values. If the student chooses to farm, her farming income is $\$ 1,000$ times her card value. These values are not private information. Students keep their values for the whole game. Post the "live" megafauna picture on the board.

You should guide students' seating to eliminate empty seats and to shape the "geography" of your experimental landscape into a compact rectangle or square. Each seat will correspond to a cell in the Excel spreadsheet, as shown in the example room layout in Figure 1. Use sticky notes to mark some cell locations (e.g. corners: A1, L1, A5, L5) so students know their positions. Empty "plots" at the ends of rows can be thought of as geographic features like mountains or lakes. ${ }^{6}$ If a student is isolated so she has only one neighbor, this confers an earnings disadvantage, so you can recruit such a student to be a data recorder or let her form a team with her neighbor. If a student arrives after the game has already begun, it is easiest to ask her to form

\footnotetext{
${ }^{6}$ If there are empty seats in the classroom at the beginning of the game, instead of treating each as a mountain or a rock, it is possible to let neighboring students take over the plot of land. This can demonstrate a situation in which spillovers across plots are internalized when one entity owns neighboring plots. Such plots could even be auctioned off. A new farming value would have to be assigned to these plots (by randomly dealing a card to it).
} 
a team with another student, though it is possible to add new arrivals to fill in "holes" in the landscape or to take plots on an edge of the landscape.

Door

Front of Classroom

Window

\begin{tabular}{|l|l|l|l|l|l|l|l|l|l|l|l|}
\hline A1 & B1 & C1 & D1 & E1 & F1 & G1 & H1 & I1 & J1 & K1 & L1 \\
\hline A2 & B2 & C2 & D2 & E2 & F2 & G2 & H2 & I2 & J2 & K2 & L2 \\
\hline A3 & B3 & C3 & D3 & E3 & F3 & G3 & H3 & I3 & J3 & K3 & L3 \\
\hline A4 & B4 & C4 & D4 & E4 & F4 & G4 & H4 & I4 & J4 & K4 & L4 \\
\hline A5 & B5 & C5 & D5 & E5 & F5 & G5 & H5 & I5 & J5 & K5 & L5 \\
\hline \multicolumn{10}{|c|}{}
\end{tabular}

Figure 1: Example Classroom Layout for 60-Student Class

Once students are seated and have their materials, ask them to record their names, card numbers (quality), and grid locations on their recording sheets. Then you must record students' card numbers in the Excel spreadsheet in the "AgQuality" worksheet, as shown in Figure 2. Since the land quality information is not private information, you can quickly go around the room and have the students call out their numbers. ${ }^{7}$

\begin{tabular}{|c|c|c|c|c|c|c|c|c|c|c|c|c|}
\hline 4 & A & B & c & D & $\mathrm{E}$ & $\mathrm{F}$ & G & $\mathrm{H}$ & I & $\mathrm{a}$ & $\mathrm{K}$ & L \\
\hline 1 & 1 & 6 & 1 & 6 & 1 & 6 & 1 & 6 & 1 & 6 & 1 & \\
\hline 2 & 2 & 7 & 2 & 7 & 2 & 7 & 2 & 7 & 2 & 7 & 2 & \\
\hline 3 & 3 & 8 & 3 & 8 & 3 & 8 & 3 & 8 & 3 & 8 & 3 & \\
\hline 4 & 4 & 9 & 4 & 9 & 4 & 9 & 4 & 9 & 4 & 9 & 4 & \\
\hline 5 & & & & & & & & & & & & \\
\hline 6 & \multicolumn{12}{|c|}{ AGRICULTURAL QUALITY } \\
\hline 7 & Fill & $d n$ & $n b$ & int & ric & ou & & & & & & \\
\hline
\end{tabular}

Figure 2: Recording Agricultural Qualities

Once you are ready to start, if you are restricting communication to between specific rounds, tell students not to speak to each other except when explicitly allowed. This lets students think independently and showcases the role of communication and information exchange in strategic decision-making. If you will only be doing one round of the border and corridor treatments, you may want to allow communication during at least those rounds, because otherwise coordination can be frustratingly difficult.

\footnotetext{
${ }^{7}$ The spreadsheet determines whether a location is populated (i.e. whether the plot of land "exists”) by looking at whether a value is entered into this cell in the AgQuality sheet. Calculations of total ecosystem services and net social welfare draw values only from plots of land that are thus determined to "exist." In this way, it is very easy to use this spreadsheet for a class that is smaller than the $5 \times 12$ grid provided: leave blank the AgQuality cells for unoccupied spaces. If the class is larger on one or both dimensions, you must make more changes to the spreadsheet.
} 
At the start of each round, describe the current policy environment and write information about the conservation incentive on the board. Emphasize to the students that each round is independent of other rounds. Then give the students time to make their decisions. Each should circle C (for Conserve) or F (for Farm) on her sheet so that she is committed to her decision before she hears others' choices. Then go around the room and have each student verbally report her decision. ${ }^{8}$ For convenience, the decisions are reported sequentially, but students should treat this as a simultaneous game. An alternative (for the treatments other than the auction) is to give each student a green and a brown piece of paper. When it's time to announce their decisions, students hold up the green if they choose to conserve and brown if they farm. They must do so simultaneously and not change their minds. This forces decisions to be (almost) truly simultaneous. Record choices in the decision block of the worksheet (which starts at column A and row 1) as zeroes (for farming) and ones (for conservation), as shown in Figure 3.

\begin{tabular}{|c|c|c|c|c|c|c|c|c|c|c|c|c|}
\hline & A & B & c & $\mathrm{D}$ & $\mathrm{E}$ & $F$ & G & H & 1 & $\mathrm{~J}$ & K & L \\
\hline 1 & 0 & 0 & 0 & 1 & 1 & 0 & 1 & 0 & & & & \\
\hline 2 & 0 & 0 & 0 & 0 & 0 & 0 & 0 & 1 & & & & \\
\hline 3 & 0 & 1 & 0 & 0 & 0 & 1 & 0 & 0 & & & & \\
\hline 4 & 0 & 0 & 1 & 0 & 0 & 1 & 1 & 0 & & & & \\
\hline 5 & & & & & & & & & & & & \\
\hline 6 & & & & & & & & & & & & \\
\hline 7 & \multicolumn{12}{|c|}{ CONSERVATION DECISIONS: ENTER DECISIONS ABOVE IN THIS BLOCK } \\
\hline 8 & Greer & co & $\mathrm{d}$; & $(0$ & med & & & & & & & \\
\hline
\end{tabular}

Figure 3: Recording Decisions

Once you have all of the decisions, you must record two more things in the worksheet: the number of conserved blocks of each size, and the number of corridors. These are shown in Figure 4. Specifically, the instructor must count the number of blocks of each block size and then enter these counts into the "\# blocks" column. This will automatically calculate the relevant ecosystem service value. Remember that blocks consist of conserved plots that are connected by shared edges (not shared corners).

\footnotetext{
${ }^{8}$ Clickers could be used to register decisions, which would make rounds go faster and would force students to commit to their strategies before learning of others' choices. To make this work, one would have to incorporate the clicker feedback into the Excel spreadsheet.
} 


\begin{tabular}{|c|c|c|c|c|c|c|c|}
\hline \multirow{3}{*}{$\begin{array}{l}16 \\
17\end{array}$} & \multirow{2}{*}{ Manually fill in \# corridors, \# blocks! } & \multirow{2}{*}{$\begin{array}{c}\mathrm{N} \\
\text { Block size }\end{array}$} & \multirow{2}{*}{$\begin{array}{c}0 \\
\text { \# blocks } \\
\end{array}$} & \multirow{2}{*}{$\begin{array}{c}\text { P } \\
\text { Value/block }\end{array}$} & \multirow{2}{*}{ Total } & \multirow{2}{*}{$\begin{array}{c}\text { R } \\
\text { Block ESS }\end{array}$} & \multirow{2}{*}{$\begin{array}{c}s \\
\$ 6,050.00\end{array}$} \\
\hline & & & & & & & \\
\hline & \# of corridors: & 1 & 1 & $\$ 50.00$ & $\$ 50.00$ & Corridor? & TRUE \\
\hline & & 2 & 3 & $\$ 100.00$ & $\$ 300.00$ & ESS & $\$ 9,050.00$ \\
\hline & & 3 & & $\$ 200.00$ & $\$ 0.00$ & & \\
\hline & & 4 & 1 & $\$ 400.00$ & $\$ 400.00$ & & \\
\hline & & 5 & 1 & $\$ 800.00$ & $\$ 800.00$ & & \\
\hline & & 6 & & $\$ 1,600.00$ & $\$ 0.00$ & & \\
\hline & & 7 & & $\$ 2,400.00$ & $\$ 0.00$ & & \\
\hline & & 8 & & $\$ 3,200.00$ & $\$ 0.00$ & & \\
\hline & & 9 & & $\$ 4,000.00$ & $\$ 0.00$ & & \\
\hline & & 10 & 1 & $\$ 4,500.00$ & $\$ 4,500.00$ & & \\
\hline & a: Number of Corridors & b: & ibe & $\begin{array}{c}\text { Blocks of } \\
\text { Service }\end{array}$ & $\begin{array}{l}\text { Each Size } \\
\text { Calculatio }\end{array}$ & and Ecc & ystem \\
\hline
\end{tabular}

Figure 4: Recording Number of Corridors and Blocks

After this has all been recorded, the spreadsheet is fully updated. Tell students the total amount of ecosystem services so that they can enter that in their recording sheet, and tell them whether the megafauna survive. (If the megafauna have changed state, remember to change the picture.) Scroll to the right of the worksheet to show students summary information for the round, including total ecosystem services and net social welfare, as well as a grid in which each subject's earnings are displayed (see Figure 5).

\begin{tabular}{|c|c|c|c|c|c|c|c|c|c|c|c|c|c|c|c|}
\hline 4 & $A H$ & Al & As & AK & AL & AM & AN & AO & AP & $A Q$ & AR & AS & AT & $A U$ & AV \\
\hline 1 & Total Earnings & $\$ 589,200.00$ & & A & B & C & D & E & $\mathrm{F}$ & G & $\mathrm{H}$ & 1 & $\mathrm{~J}$ & K & $\mathrm{L}$ \\
\hline 2 & Total Conservation Payments & $\$ 111,000.00$ & 1 & $\$ 13,050$ & $\$ 13,050$ & $\$ 13,050$ & $\$ 13,050$ & $\$ 14,050$ & $\$ 13,050$ & $\$ 13,050$ & $\$ 13,050$ & $\$ 13,050$ & $\$ 14,050$ & $\$ 13,050$ & \\
\hline 3 & Net & $\$ 478,200.00$ & 2 & $\$ 13,050$ & $\$ 16,050$ & $\$ 11,050$ & $\$ 16,050$ & $\$ 12,050$ & $\$ 16,050$ & $\$ 11,050$ & $\$ 16,050$ & $\$ 11,050$ & $\$ 13,050$ & $\$ 11,050$ & \\
\hline 4 & & & 3 & $\$ 14,050$ & $\$ 13,050$ & $\$ 12,050$ & $\$ 17,050$ & $\$ 12,050$ & $\$ 12,050$ & $\$ 14,050$ & $\$ 14,050$ & $\$ 13,050$ & $\$ 14,050$ & $\$ 12,050$ & \\
\hline 5 & Total ESS & $\$ 398,200.00$ & 4 & $\$ 12,050$ & $\$ 18,050$ & $\$ 13,050$ & $\$ 12,050$ & $\$ 12,050$ & $\$ 18,050$ & $\$ 13,050$ & $\$ 13,050$ & $\$ 13,050$ & $\$ 12,050$ & $\$ 13,050$ & \\
\hline 6 & & & 5 & & & & & & & & & & & & \\
\hline 7 & & & & & & & & & $E A$ & INGS & & & & & \\
\hline
\end{tabular}

Figure 5: Summary of Earnings, Ecosystem Service Values, and Net Social Welfare

Before moving onto the next treatment, ask the students to briefly reflect on what happened and compare the outcomes from the current treatment with the previous treatments. This can lay the groundwork for a richer discussion at the end of the game.

\section{Ecosystem Services and Megafauna Survival}

Ecosystem services are a public good: every landowner gets the same ecosystem service benefits. Ecosystem services, including megafauna survival, are provided based on the amount and arrangement of conserved land. Having larger connected blocks of conserved land often yields greater ecological benefits, though there may be diminishing benefits to increasing the size of a conserved block after a certain point.

We define a block as any group of conserved cells that are linked by shared edges. Table 1 shows how the ecosystem value generated by a block $(E Z)$ varies with the size $(Z)$ of the block. 
The total ecosystem service benefits provided in a round is the sum of the benefits provided by each block of conserved land.

\begin{tabular}{|cc|}
\hline $\begin{array}{c}\text { Block Size } \\
(Z)\end{array}$ & $\begin{array}{c}\text { Ecosystem Value } \\
(E Z)\end{array}$ \\
\hline 1 & $\$ 50$ \\
2 & $\$ 100$ \\
3 & $\$ 200$ \\
4 & $\$ 400$ \\
5 & $\$ 800$ \\
6 & $\$ 1,600$ \\
7 & $\$ 2,400$ \\
8 & $\$ 3,200$ \\
9 & $\$ 4,000$ \\
10 & $\$ 4,500$ \\
11 & $\$ 4,700$ \\
12 & $\$ 4,800$ \\
13 & $\$ 4,850$ \\
14 & $\$ 4,900$ \\
15 & $\$ 4,950$ \\
$16+$ & $\$ 5,000$ \\
\hline
\end{tabular}

Table 1: Ecosystem Service Values for Blocks of Conserved Land

Students may notice a pattern in the way ecosystem service values vary with the size of a conserved block of land. For small to moderate sizes of blocks, total value increases with increasing agglomeration: for example, a block of four conserved plots provides more benefits than do four isolated conserved plots. As blocks get even larger, this agglomeration benefit slows and eventually reverses, so increasing block size is eventually associated with decreasing total value. For example, a block of sixteen conserved plots provides less benefit than do two blocks of eight plots each. In natural landscapes, agglomeration benefits may occur as conserved land areas become large enough to support ecosystem elements like specific species. Agglomeration may instead cause benefits to decline in some cases: subpopulations large enough to survive on their own may do well to be isolated so diseases that afflict one group cannot spread to other groups, and the concavity of the species-area curve (Preston, 1962) means that multiple separate reserves allow more species to thrive. If you want to de-emphasize this latter element, you can change the ecosystem values so they no longer diminish in block size for larger blocks.

Additionally, the charismatic megafauna are only preserved if a corridor of land connecting the two short edges of the classroom is conserved. If at least one corridor is formed, the megafauna are preserved (so you show the "live" picture) and ecosystem service benefits increase by the megafauna survival (MS) value of $\$ 3,000$. If no corridors are formed, the megafauna die (so you show the "dead" picture). 
Ecosystem services are therefore:

ESS $=$ E1*\# of 1-plot blocks $+\ldots+$ E16*\# of 16+-plot blocks + MS

where the EZ's (E1-E16) are specified in Table 1 and $M S$ is the megafauna survival value.

The ecosystem values can be changed for different class sizes, but it is essential that at least for the vast majority of landowners it is not privately optimal to choose conservation, and that it is socially optimal to have some (but not universal) conservation.

\section{Treatment 1: Flat Conservation Payment}

This is the simplest treatment and should be run first. In this treatment, if a landowner chooses to conserve, she receives a flat conservation payment of $\$ 2,000$. Since students have farming values that range from $\$ 1,000$ to $\$ 10,000$, the only students who choose to conserve will be those with a value of $\$ 1,000$ or $\$ 2,000$ and those who are willing to sacrifice their own payoff for the goal of conservation.

\section{Treatment 2: Border Conservation Payment}

This treatment adds one spatial element to the incentive scheme. Now a landowner who conserves gets a bonus of \$1,000 for each edge her plot shares with a conserved cell (in addition to her $\$ 2,000$ flat payment), for a maximum of $\$ 6,000$ conservation payment if all four edges are shared with conserved plots. There is now strategic uncertainty and an issue of coordination. If a student knows that a neighbor will conserve then it may be worth her while to do so as well.

To let students work through issues of coordination and trust, it is best to play two rounds of this treatment. Allow no communication during each round in which you implement this treatment but let students talk to each other briefly (for about five minutes) between rounds. If there is only time to run one round, however, you should let students talk before they make decisions.

\section{Treatment 3: Corridor Conservation Payment}

This treatment adds a different spatial element. The government may want to incentivize the formation of a corridor so that the charismatic megafauna can be preserved. In this treatment, anyone who is part of a successful corridor receives a $\$ 2,000$ conservation payment plus a $\$ 3,000$ corridor bonus. In different classroom shapes, the corridor bonus might be increased or decreased. If multiple corridors are formed, the shortest one gets the bonus. If there are multiple corridors of the shortest length, you could subsidize members of all of them, but we prefer to choose one randomly. ${ }^{9}$ If there is a corridor, you must then type the cell locations of all cells that are in the eligible corridor into the indicated cells in column A, as shown in Figure 6.

\footnotetext{
${ }^{9}$ The random choice is done as follows. You will have entered how many eligible corridors exist (the number of shortest corridors) into the spreadsheet. A random-number generator in an adjoining cell will generate a random integer from 1 to the number you entered, and it will re-generate this each time any calculation or entry is performed in the sheet. You can build suspense and call students attention to the calculation moment, and enter the number of
} 


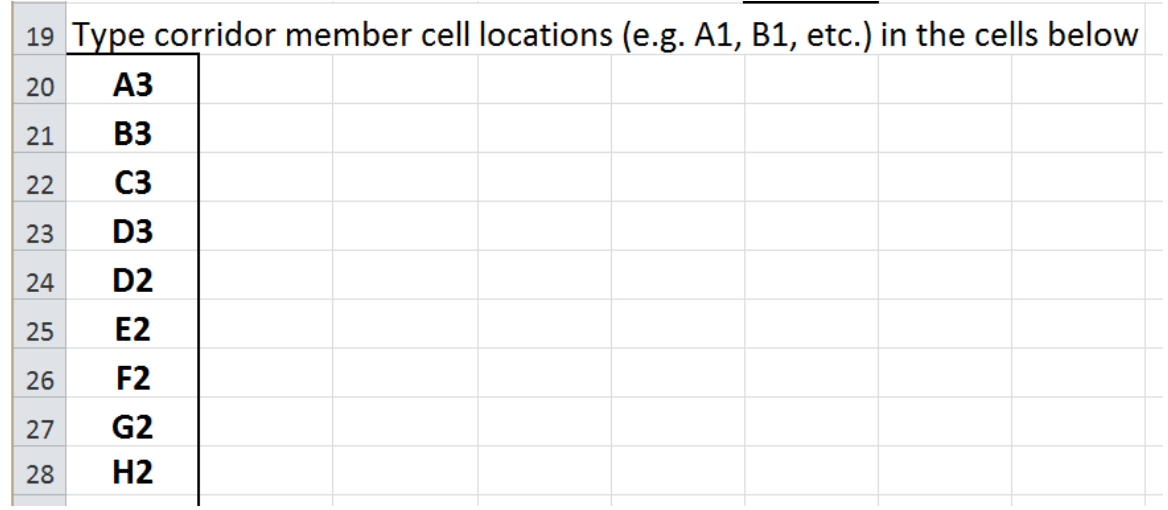

Figure 6: Recording Members of Eligible Corridors

A corridor bonus incentivizes a certain kind of block, and even failed attempts at corridors can result in increased conservation. However, the pattern of conserved land will differ significantly between this and the border payment treatment.

Since coordination is the key to receiving the conservation bonus in this context, it is again best to allow no communication, do a round of this treatment, allow discussion, and then do another round. Again, if there is not enough time, you can instead do a single round during which you allow communication.

\section{Treatment 4: Conservation Auction}

This treatment focuses on the costs, and not the benefits, of conservation. In this treatment, each subject makes a conservation payment bid. The lowest $50 \%$ of the bids are accepted. Point out that this conservation auction is similar to the Conservation Reserve Program and other policies.

In this treatment, each subject writes down not a binary decision of $\mathrm{C}$ or $\mathrm{F}$, but instead a bid value. If her bid wins then she receives as her conservation payment the value she bid. This is not theoretically incentive-compatible, but is easier for students to understand than a second-price auction. Record student bids into the spreadsheet bid column (column X) as shown in Figure 7. Break critical ties (ties at the winning bid) randomly if there are any. ${ }^{10}$ Then tell students whether their bids were accepted so they can learn whether they farmed or conserved.

corridors, and announce what random number is generated. Since the random number will continue to regenerate with every entry or calculation in the sheet, copy or type the chosen number in the cell marked "permanent."

${ }^{10}$ If there is a critical tie, go to the bid.tie sheet and sort ascending by bid and then rand(); then choose the top bids up to the maximum number of bids and inform the students who won the auction. Go back to the main sheet and manually fill in "0" in the “Accepted?" column for the tie-break losers. 


\begin{tabular}{|c|c|c|c|c|c|}
\hline U & V & W & X & Y & $Z$ \\
\hline Position & Exists? & Quality & Bid (Fill In!) & Rank & Accepted? \\
\hline A1 & TRUE & 1 & $\mathbf{1}$ & 25 & 0 \\
\hline A2 & TRUE & 2 & $\mathbf{2}$ & 21 & 1 \\
\hline A3 & TRUE & 3 & $\mathbf{3}$ & 17 & 1 \\
\hline A4 & TRUE & 4 & $\mathbf{4}$ & 13 & 1 \\
\hline A5 & FALSE & 0 & $\mathbf{0}$ & 29 & 0 \\
\hline B1 & TRUE & 6 & $\mathbf{6}$ & 10 & 1 \\
\hline B2 & TRUE & 7 & $\mathbf{7}$ & 7 & 1 \\
\hline B3 & TRUE & 8 & $\mathbf{8}$ & 4 & 1 \\
\hline B4 & TRUE & 9 & $\mathbf{9}$ & 1 & 1 \\
\hline
\end{tabular}

Figure 7: Recording Conservation Auction Bids

\section{After the Rounds}

At the end of class, go to the Summary worksheet to show students summary information for each round (see Figure 8). Discuss and compare the outcomes from the different treatments.

\begin{tabular}{|c|c|c|c|c|c|c|c|c|}
\hline $\mathrm{J}$ & $\mathrm{K}$ & L & & & $\mathrm{N}$ & & & $P$ \\
\hline Random Subject & 3 & Earnings & $\$$ & 7.03 & Conversion rate & $\$$ & $2,000.00$ & \\
\hline Random CP & 1 & & & & Raw earnings & $\$$ & $14,050.00$ & \\
\hline
\end{tabular}

Nonexistent subjects can be deleted before picking a winner; or you can just recalculate if you choose a nonexistent subject until you land on a real subject

\begin{tabular}{|r|l|lc|lr|lr|l|}
\hline CP & Trtment & Ecosystem Services & Conservation Payments & Earnings & & Net Welfare \\
\hline 1 & Flat & $\$$ & 533,950 & $\$$ & 122,000 & $\$$ & 825,950 & $\$ 703,950$ \\
\hline 2 & Border & $\$$ & - & $\$$ & 4,000 & $\$$ & 325,000 & $\$ 321,000$ \\
\hline 3 & Border & $\$$ & 8,850 & $\$$ & 6,000 & $\$$ & 329,850 & $\$ 323,850$ \\
\hline 4 & Corridor & $\$$ & - & $\$$ & 2,000 & $\$$ & 325,000 & $\$ 323,000$ \\
\hline 5 & Corridor & $\$$ & - & $\$$ & 2,000 & $\$$ & 325,000 & $\$ 323,000$ \\
\hline 6 & Auction & $\$$ & 472,000 & $\$$ & 90,000 & $\$$ & 796,000 & $\$ 706,000$ \\
\hline
\end{tabular}

Figure 8: Summary Information and Random Payee Selection

Randomly pick one or a few students to be paid. You could do this by bringing a stack of index cards with locations written on them and shuffling the stack and picking one, but the Summary sheet of the Excel workbook has a built-in tool for doing this, as shown in Figure 8. Explain that a random number generator will choose a person and a contract period to pay when you type something in a cell. This random number generator generates a new number every time a calculation or entry is performed in the sheet. Build up some suspense and then type anything 
anywhere to get the random number generators to choose new values for "Random CP" and "Random Subject." Declare the winner and the amount, and pay in cash immediately. If you want to pay multiple students, simply create more random number generators for this purpose, or force the random number generator to regenerate multiple times, saving the resulting locations and earnings amounts each time. With our parameters, earnings for a student in each round can range from $\$ 0.50$ to about $\$ 15.50$, but they usually are between $\$ 1$ and $\$ 9$.

Instead of paying students in cash, you can pay the randomly-selected earnings to a non-profit of your (or the students') choice-perhaps a local land conservation group. Alternatively, you can compensate students in extra credit: you can choose the five students with the highest earnings (or the highest ratio of actual earnings to earnings that would be possible given their farming value card, so that students who randomly received lower cards are not disadvantaged) and give them some flat number of extra credit points.

Save the spreadsheet with the class's data and post it to the course website so that students can see it. Students can keep instructions and recording sheets.

\section{Discussing the Game}

After the students play the game, there are many fruitful directions for discussion, either in class after the game, during the next class session, or through online discussion boards. Instead or in addition, you might ask students to write up their reflections on the game (perhaps in response to discussion questions you provide) and hand those write-ups in or post them to a common forum. In this section, we give questions you can use as writing prompts or to guide in-class discussion.

You can prompt discussion about the economic decision-making process. Discussion questions include "How did you make your decisions?" and "Did you think that you and others made the best decisions?” Encourage students to think both about profit maximization and any other goals that they might have. Note that modern theory does not consider it irrational to have preferences over others' payoffs, and these might drive some contributions to public goods; you can refer to literatures on types of altruism, e.g. Andreoni (1989), for example. There may also be intrinsic preferences for conservation (Chouinard et al., 2008). Encourage students to think carefully about what this means, and perhaps to reflect on the role of anthropocentrism in environmental economics. Students may also reflect on the possible importance of reputation concerns and social interactions in both their actions and in real-world policy contexts.

A very productive discussion can reflect on the policies in the treatments. You can ask a general question like "What are the pros and cons of the different conservation payment schemes we tried?” and follow threads proceeding from that. You can also ask how realistic students think these policy scenarios are, and how politically palatable they might be. You can also ask more specific questions about the particular policies, like, "Are spatially explicit policies preferable to policies that emphasize costs?” You can keep the spreadsheet visible to help students think 
through counterfactuals: they might think that farmers are less able to communicate and collude than they could in the classroom, for example, so you can simulate how that might change decisions and therefore the outcomes of the different policies.

Discussions that are directly about conservation policy are appropriate for many classes. Students often like to be asked to come up with local examples of land use issues and to reflect on how these policies might work in their local settings. Such a discussion might lead them to ask whether the same policies are best for all locations. Another interesting area for discussion is species conservation: you can talk about which species should be conserved, the role of charismatic species in motivating conservation (Andelman and Fagan, 2000; Clucas et al., 2008; The Economist, 2008), and whether students think their conservation decisions would be different if the vulnerable species was not so charismatic. You can also discuss how the duration of the contracts may influence landowners' decisions and conservation and economic outcomes; for example, temporary conservation contracts may perversely encourage more intensive use later (Jacobson, 2014).

The experiment can also be used to get students to think distinctly about the costs of conservation and the benefits of conservation. You can ask them to identify what falls into the cost column and what falls into the benefits column. Once you've done that, you can ask them how we make a social decision considering all of these costs and benefits. A key point is that the costs and benefits may be denominated in different terms, so we need some way to weigh them

against each other. This is highlighted in this experiment because the pattern of conservation that results from a cost-minimization focus is very different from the pattern that results from a benefits-maximization focus, so some tradeoffs must be made between costs and benefits. This can lead into a conversation about the role of valuation, or into more philosophical territory about whether it is acceptable or necessary to value costs and benefits in dollar terms.

\section{Evidence of Pedagogical Effectiveness}

In this section we discuss what happened when we played the game in our classes at Colby College (in Spring 2014) and Williams College (in Spring 2015).

The decision data show that students responded strongly to the economic incentives they faced. The structure of the incentives differed across the two schools, so we analyzed the data from each separately. The border bonus increased conservation, significantly at Colby but not significantly at Williams. This difference may have arisen because we provided different ecosystem service values, or perhaps there were idiosyncratic differences in ability to "collude" with neighbors. The corridor bonus did not affect conservation at Colby, so we increased the bonus payment amount significantly when we used it at Williams and it was tremendously effective there. Students were far more likely to conserve if they had a lower agricultural quality, and indeed quality drove nearly half of the variation in the conservation decision. Finally, auction bids were strongly correlated with agricultural quality, with a coefficient very close to 
one. However, there was some voluntary conservation: with flat conservation payments, nearly everyone with an agricultural quality at or below 2 (the amount of the flat payment), choose to conserve, in line with financial incentives, but $75 \%$ of the people with quality of 3 also did so, as did $12.5 \%$ of those with higher qualities, even though everyone with a value of 3 and above has an incentive to farm.

We also got feedback from in-class debriefing and on-line questionnaires. Students identified three main takeaways from this game. First, they gained a practical understanding of the importance of incentives and trade-offs with regard to land conservation (and economics broadly). One student commented that "Not everyone has to conserve land, only those for which it is economically plausible.” Another said, "People are (almost) always going to act solely based on personal financial incentives, but with the right setup they can be coerced into conserving their land when they otherwise would not have." A third said, "It seems that the corridor option was most effective, yet this was definitely a lot more expensive for the government to implement, and since farming was not incentivized in the corridor case, it may be the case that you want more of a balance between farming and conservation that such a policy might prevent."

Second, the students learned about the importance of spatially targeted policies for land conservation and how these policies can be more effective than flat conservation payments ("The border bonus was the best way to get a group of selfish-minded individuals to work together toward conservation of significant chunks of land.”). The students also realized that auctions can result in scattered plots of conserved land (which lead to a decrease in the value of the conserved land), but that auctions can conserve land more cost-effectively ("The auction system would require less resources and will most likely conserve more land.”).

Third, the students understood the importance of communication and coordination in trying to achieve higher social welfare. As one student said, "having conservation incentives that make people want to convince their neighbors to conserve are generally effective.” Another said of the corridor bonus, "It requires a lot of communication, but if people agree to conserve it makes a huge difference.” When communication was allowed between spatial incentive treatments, there was generally more conservation after communication.

Most students identified the corridor or border bonus (in part depending on the outcomes they observed in class) as the most effective land conservation policy and stated that it was because these policies encouraged communication and coordination amongst neighbors and achieved more conservation and thus a higher ecosystem service benefit.

Overall, the feedback from the students indicates that the game was very successful in achieving the learning objectives. As one student said:

"The game gave me a better idea of the types of conservation policies that can be implemented in order to achieve certain outcomes like cost effective conservation or maximizing the size of contiguous conservation land. It also was useful to be in the shoes 
of a person deciding what to do with their land because it showed how it can sometimes be difficult to conserve even when you want to due to the incentives at play.”

\section{Extensions and Modifications}

This game is relatively flexible, as are the materials we share. They will work seamlessly for 60 or fewer students and rooms of dimensions 5 seats by 12 seats or less. The spreadsheet must be modified for rooms larger on one dimension or the other. It must also be modified if you wish to run more of any of the treatments than the spreadsheet we provide allows for.

To fine-tune the game to issues more central to your course or your local area, you can reframe the actions students can take without changing incentives. For example, instead of being farmers deciding between farming (the brown activity) and conservation (the green activity), you can cast them as landowners deciding between farming (the green activity, as it provides greenspace and some ecosystem services) and development (the brown activity). This may be particularly relevant if your school is located in an urban area. You could even reframe the game to not be about land at all but about, say, enrolling youth from a rough neighborhood in job training programs. People may have different opportunity costs of program enrollment (different demands from family, different outside options), and may also have different degrees of social spillovers on neighbors and family members (so different social benefits of participation). The same concepts of trading off independently-varying costs and benefits arise in many social policy situations.

Within the context in which you run the experiment, you can create new treatments to showcase other ideas. We presented three treatments that incentivize particular patterns of conservation based on benefits of conservation and one that incentivizes participation based on costs. You could combine two of these schemes; for example, you could do a conservation auction that also pays some form of spatial bonus. This is complicated but it can highlight the fact that to consider both benefits and costs we need some way of making a tradeoff between the two quantities. You could also modify any of the treatments to incorporate realistic policy features; for example, you could add a government budget to the auction treatment so that bids will only be accepted up to a maximum total payout.

For a simpler game, or if you have more time available, you can start with a round in which the government offers no conservation payments. This will also elicit the extent of social or conservation preferences of the class and provide an absolute baseline to which to compare the other treatments' outcomes. In this treatment, profit-maximizing students should never choose conservation since their earnings from the ecosystem services created on their own land is always less than potential income from farming. You could implement this as a single round or as two rounds with communication allowed between them to see whether collusion arises when the benefits of so doing result only from ecosystem services rather than also coming from government payments. 
You could also add more realism on many dimensions of the model of the economic situation. For example, the game we present assumes farmers are price takers, which reduces complexity of play. If you want to demonstrate implications of market interconnections, you can make the returns to farming a function of the number of farmers as would be the case in a general equilibrium setting. Markets can also interact through environmental consequences of actions: you could define one part of the room as upstream and one part as downstream, and farms downstream could see their returns to farming reduced when more upstream landowners farm. This illustrates directional flow issues and allows for Coasian bargaining solutions.

If the course covers uncertainty, you can add random shocks to any element. This can represent the effects of climate change on agriculture. For example, if you want to show how conservation payments can act as insurance, you can add uncertainty (a mean preserving spread) to the return to farming. You can do this by adding a "Realized Farming Income" column that differs from the "Farming Income" column by a random offset or multiplier. The shock can be created by a manual die-roll (e.g., you could roll a six-sided die; income is reduced by $\$ 1,000$ if a one is rolled, increased by $\$ 1,000$ if a six is rolled, and remains unchanged otherwise). Alternatively, you can use the rand() function in Excel; for example, you could create a multiplicative factor equal to (rand() times 0.4 minus 0.2 ), which generates a value from -0.2 to +0.2 . (If you use rand(), since the function recalculates each time you edit the spreadsheet, copy the realized numbers and the paste their values to make them permanent.) The idea of conservation payments as insurance could also be presented in the context of developing countries in which payments for environmental services programs may offer a green route out of poverty.

Another way to add climate change-based uncertainty into the game is to add a dynamic element to the experiment. Future farming or ecosystem values could change based on a random shock that simulates climate change-based outcomes, and the likelihood of this shock could be a function of past farming decisions. This randomness could again be implemented using a die roll or the rand() function in Excel.

\section{Conclusion}

In this paper, we describe a classroom game that demonstrates concepts central to land conservation and more generally to policymaking tradeoffs between benefits and costs. We have refined the game through play at two different institutions, and we found that our students enjoyed the game and learned important lessons from it. The game is flexible enough to be tuned to a variety of class sizes and focuses, and it can be extended to cover a variety of topics. We hope your students will also find this to be a fruitful way to learn this material! 


\section{Appendix I: Instructions and Recording Sheet}

\section{Overview}

\section{Land Conservation Game}

The classroom space represents an area of land in rural Massachusetts. You are a farmer, and you own a plot of land. The location of your land within the larger area is the location of your seat in the classroom. The agricultural quality of your land is determined by the number (1-10) on the card you were dealt.

The state of Massachusetts and the federal government have identified this land as having ecological value and want to encourage farmers to conserve some land instead of farming it. To this end, over the coming years, the government will try different payment schemes to enroll farmers like you in conservation contracts for fixed contract periods (which last 10 years each). In each contract period, you and the other farmers will individually decide whether you choose to farm or conserve your land. These decisions will determine your earnings in each contract period. Each contract period is independent of the other periods: choices in one period do not affect outcomes in other periods.

At the end of today's class, one student will be picked at random, and then one contract period will be picked at random. That student will be paid his or her earnings from the chosen contract period in cash, at a rate of $\$ 1$ per $\$ 2,000$ earned in the round. Since you may be chosen to be paid, and since your choices in each contract period may affect your earnings, you should attend to all of your decisions carefully.

\section{Your earnings:}

In each contract period, your earnings are:

$$
\text { Earnings }=\text { Farming Income }+ \text { Conservation Payments }+ \text { Ecosystem Services }
$$

Farming Income: if you do not farm, your farming income is zero. If you farm, your farming income equals the agricultural quality of your land (the number on your card) times $\$ 1,000$.

Conservation Payments: if you farm, your conservation payments are zero. If you do not farm and instead conserve, you get a conservation payment from the government. The size of the conservation payment depends on the current conservation payment policy and may also depend on the farming decisions of the farmers around you.

Ecosystem Services: everyone benefits from ecosystem services provided by conserved land. These benefits include habitat for animals like moose and turkey. Fragmented habitat is less able than contiguous habitat to support wildlife. Therefore ecosystem services depend on the number (\#) and size (Z) of connected blocks of conserved land as listed in Table 1.

There is another ecosystem service benefit when a contiguous corridor of conserved land lets moose migrate from one side of the room to the other. A value of $M S$ (megafauna survival) $=\$ 3,000$ is added if at least one single path of land from left to right is contiguously conserved. There is no added benefit from an additional corridor when one has been formed; nor does a wider corridor create more benefit. The total Ecosystem Services benefit (ESS) is:

$$
\text { ESS }=\text { E1 }{ }^{*} \# \text { of 1-plot blocks }+\ldots+E 16^{* \#} \text { of 16+-plot blocks }+ \text { MS }
$$

where E1-E16 are as in Table 1 and MS is the value of megafauna survival.

\begin{tabular}{|cc|}
\hline Block & Ecosystem \\
Size $(Z)$ & Value $(E Z)$ \\
\hline 1 & $\$ 50$ \\
2 & $\$ 100$ \\
3 & $\$ 200$ \\
4 & $\$ 400$ \\
5 & $\$ 800$ \\
6 & $\$ 1,600$ \\
7 & $\$ 2,400$ \\
8 & $\$ 3,200$ \\
9 & $\$ 4,000$ \\
10 & $\$ 4,500$ \\
11 & $\$ 4,700$ \\
12 & $\$ 4,800$ \\
13 & $\$ 4,850$ \\
14 & $\$ 4,900$ \\
15 & $\$ 4,950$ \\
$16+$ & $\$ 5,000$ \\
\hline
\end{tabular}

Table 1 


\section{Game Play and Scenarios}

There are six contract periods. In each contract period, you will decide whether to farm or conserve your land. Each contract period has a conservation payment available. After decisions are made for each period, the government will record all decisions and you will calculate your earnings.

\section{Contract Period 1: Flat Conservation Payment}

The government offers a fixed conservation payment of $\$ 2,000$ for each plot conserved.

\section{Contract Periods 2 and 3: Border Bonus}

The government offers a conservation payment of $\$ 2,000$ for each plot conserved, and also pays a bonus of $\$ 1,000$ for each border a conserved plot shares with another neighboring conserved plot on any of its four sides. The maximum conservation payment per plot is thus $\$ 6,000$.

\section{Contract Periods 4 and 5: Corridor Bonus}

The government offers $\$ 2,000$ for each conserved plot, and also pays a special "corridor bonus." A corridor is any path of contiguously conserved land at least one row wide that leads from the left side of the room to the right side of the room. This may be a straight left-to-right line, or it may involve turns. (Since the path must always be at least a row wide, a turn requires more plots of land to be involved!) If a plot of land is part of an eligible corridor, then that plot's owner receives an additional $\$ 3,000$.

However, the government will only pay a bonus for one conserved corridor. If there are two or more corridors, only one corridor is eligible: the government will consider only the corridor(s) that make the shortest paths (fewest plots of land), and if there are more than one of those, it will randomly pick one of them to receive the corridor bonus, and the plots in other corridors will just receive the $\$ 2,000$ conservation payment.

\section{Contract Period 6: Auction}

Farmers submit bids that represent the payment they would accept to conserve their land. The government takes the lowest $50 \%$ of the bids. (If there is a tie at the winning bid, it will be broken randomly.) For each successful bid, the farmer conserves his or her land and receives a subsidy payment equal to his or her bid. Farmers who submit rejected bids farm their land. 


\section{Decision and Earnings Worksheet}

My Agricultural Quality (Card Number):

My location (circle in grid below):

Door

Front of Classroom

Window

\begin{tabular}{|c|c|c|c|c|c|c|c|c|c|c|c|}
\hline A1 & B1 & C1 & D1 & E1 & F1 & G1 & H1 & I1 & J1 & K1 & L1 \\
\hline A2 & B2 & C2 & D2 & E2 & F2 & G2 & H2 & I2 & J2 & K2 & L2 \\
\hline A3 & B3 & C3 & D3 & E3 & F3 & G3 & H3 & I3 & J3 & K3 & L3 \\
\hline A4 & B4 & C4 & D4 & E4 & F4 & G4 & H4 & I4 & J4 & K4 & L4 \\
\hline A5 & B5 & C5 & D5 & E5 & F5 & G5 & H5 & I5 & J5 & K5 & L5 \\
\hline
\end{tabular}

Back of Classroom

My decisions and my earnings (fill in the table below as the contract periods progress):

\begin{tabular}{|c|c|c|c|c|c|c|c|}
\hline $\begin{array}{c}\text { Contract } \\
\text { Period }\end{array}$ & $\begin{array}{c}\text { Subsidy } \\
\text { Type }\end{array}$ & Bid & Choice & $\begin{array}{c}\text { Farming } \\
\text { Income }\end{array}$ & $\begin{array}{l}\text { Conserv. } \\
\text { Payment }\end{array}$ & $\begin{array}{c}\text { Ecosystem } \\
\text { Services }\end{array}$ & Earnings \\
\hline 1 & Flat & & $\mathrm{F}$ or $\mathrm{C}$ & $\$$ & $\$$ & $\$$ & $\$$ \\
\hline 2 & Border & & $\mathrm{F}$ or $\mathrm{C}$ & $\$$ & $\$$ & $\$$ & $\$$ \\
\hline 3 & Border & & $\mathrm{F}$ or $\mathrm{C}$ & $\$$ & $\$$ & $\$$ & $\$$ \\
\hline 4 & Corridor & & $\mathrm{F}$ or $\mathrm{C}$ & $\$$ & $\$$ & $\$$ & $\$$ \\
\hline 5 & Corridor & & $\mathrm{F}$ or $\mathrm{C}$ & $\$$ & $\$$ & $\$$ & $\$$ \\
\hline \multirow[t]{2}{*}{6} & Auction & $\$$ & $\mathrm{~F}$ or $\mathrm{C}$ & $\$$ & $\$$ & $\$$ & $\$$ \\
\hline & & & & & & TOTAL & $\$$ \\
\hline
\end{tabular}




\section{Appendix II: Instructor’s Guide}

This document gives specific instructions for the instructor who plans to use this game in class.

In advance:

- Make changes to the spreadsheet if necessary

o Make sure your classroom size is congenial to the grid (no larger than the grid provided; smaller is OK); modify grid if necessary.

o Plan which treatments to run and how many times you will run each, and if necessary make copies of the Excel worksheets of treatments you plan to run more times than is currently provided for. (The spreadsheet is initially set up for six rounds: 1 - flat; $2 \& 3$ - border; $4 \& 5$ - corridor; and 6 - auction.) If you do make copies, modify the "Summary" sheet to add columns that link to these new sheets.

o If you would like to increase or decrease possible earnings of the winning subject, change the "Conversion rate" in cell M1 of the "Summary" sheet.

- Send instructions to students (along with any desired supplemental readings) and tell them to read them before class.

Bring:

- Copies of instructions and recording sheets

- Playing cards: Ace-10 all suits, at least enough to give one to each student (but a uniform distribution across the values), shuffled

- Paper or sticky notes for marking grid locations (especially row ends)

- Picture of “alive” and “dead” megafauna (e.g., Bullwinkle Moose)

- Optional: one green and one orange or brown piece of paper per student

- Money (a ten, a five, four ones, and three quarters) if you will pay in cash

Room setup:

- Bring up the spreadsheet on classroom computer and project it on the projector

- Make sure Excel is set to automatically perform calculations

- Mark each end of each row with paper or stickie with grid locations: e.g. A1, L1, etc. up to A5, L5. You may also want to mark some point in the middle of each row.

- Post the "live" megafauna picture on the board

Getting started in class:

- Nudge students to make as complete a grid as possible; allow empty seats on the ends but no empty plots in the middles of rows.

- Hand out instructions and recording sheets. 
- Randomly hand out cards (these are not private so they can show them to each other).

- Ask students to record name, card number (Quality), and grid location on recording sheet.

- If you will be allowing communication only at designated times, tell students that (and chide them if they start chatting).

- Explain the overall idea of the game: to learn about land conservation contracts of different kinds. Remind them that a lucky student will get paid his/her earnings from one round, so they should pay attention. Also note that if a corridor is made, the megafauna will live (show the live picture); if not, it will die (show the dead picture).

- Instruct students that for each round, they must make decisions individually and independently. They should write down their decisions to commit to them. For speed, we will get everyone's decisions verbally, but they should treat this as a simultaneous game.

- On the Excel spreadsheet, open the AgQuality sheet. Go around the room to get each student's farming value to fill into the grid.

- If new students arrive after the rounds of play have begun, it's easiest to ask each to team up with another student who's already playing, but it's also possible to give them a card and seat them at the end of a row or column, particularly if that fills out the grid.

Rounds of play:

- Explain the conservation payment scheme and write it on the board.

- Tell students to make their decisions and commit to them by writing them on their recording sheets.

- Collect everyone's decisions either by going around the room and having students verbally announce their decisions or (for treatments other than the auction) by having them hold up their green paper to represent conservation or their brown paper to represent farming. Enter all decisions into the spreadsheet: zeroes and ones in the grid for the nonauction treatments, and bids in column $\mathrm{X}$ for the auction treatment.

o For the auction treatment, the spreadsheet will automatically rank the bids and determine the lowest $50 \%$.

o The only way this ranking will be wrong is if there are enough ties at the critical bid value (the highest winning bid) such that some bids of that amount must win and some must lose. If there are such ties, too many parcels (more than 50\%) will be conserved. You can allow this to happen, or you can manually change the "Accepted" column for some of these bids from 1 (formula-calculated) to 0 . We recommend doing this randomly, by going to the bid.tie sheet of the spreadsheet, sorting by Bid then by Rand(), and selecting the bids with the highest random number. Enter 0 in the "Accepted" column for those that lost the tie-break.

- Manually fill in number of blocks of each size: count the number of blocks of each size (blocks must be connected by edges, not corners) and fill those counts into the block count column.

- Manually fill in the number of corridors. 
o If there are multiple corridors and it is the Corridor Bonus treatment, choose the corridor(s) of the shortest length (turns are allowed). If there are still multiple eligible corridors, you can either pay all of them or randomly pick one corridor for payment. We prefer the latter, which we execute by simply taking the "random \#" cell from C18 and typing its value into "permanent" in cell E5. The corridors can be intuitively ordered from the top and left.

o In the Corridor Bonus treatment, type the cell locations (e.g. A1, etc.) of all students who will receive the bonus.

- The spreadsheet then calculates everything else. Show students the "ESS" (ecosystem services) value and whether there is a corridor, both of which are in column S.

- If there is at least one corridor, leave the live megafauna picture up; if not, swap it for the dead megafauna picture.

- Scroll to the right in the spreadsheet to show the total earnings, conservation payments paid out, earnings net of conservation payments, ecosystem services provided, and everyone's earnings in a grid.

- If you are doing repeated rounds of a treatment with discussion between (which is particularly interesting for the border and corridor treatments), you can just let the students chat amongst themselves without guiding their discussion, but we recommend limiting the discussion to five minutes or less.

After all rounds:

- Go to the Summary worksheet and show the summary information for total welfare and other values of interest across the periods.

- If you are randomly picking one or more student(s) to be paid for one round, simply type some value anywhere in the spreadsheet to make the random number generators regenerate. Cells K1, K2, and M1 will then identify which plot of land has been selected to be paid and for which period, and what this subject's earnings are.

o If some plots of land in the 12 x 5 grid are unpopulated, you can delete those plots from the summary earnings table to ensure that one of those isn't accidentally picked for payment; but it is easier to leave them be and simply re-run the random number generators if one of them is chosen.

o If the winning plot of land is managed by a pair of students, they both earn the joint earnings amount.

o If you want to pay more than one student, just run the random number generators a second time to pick the second student and round, etc.

- Save the spreadsheet with the data and post to the course website so students can see it.

- Students can keep instructions and recording sheets. 


\section{Appendix III: Handout on Public Goods}

This handout provides a brief primer on externalities, public goods, land conservation, and ecosystem services. You can distribute it in whole or part to your students.

\section{Public Goods and Externalities in a Land Conservation Context}

by Sahan Dissanayake and Sarah Jacobson

Economists often say that individuals following their self-interest will unwittingly make the choices that make society overall best off (as efficient as possible). This idea goes back to Adam Smith's description (in The Wealth of Nations) of an "invisible hand" that moves goods and services efficiently from sellers to buyers. This implies that a free market, without regulation from the government, is efficient. However, economists acknowledge that this is only true under special circumstances, and those circumstances often do not hold in situations involving the environment because of externalities and public goods issues.

An externality is a situation in which the people who choose to engage in a transaction are not the only people affected by it: there are costs or benefits that accrue to others. For example, if I buy a sandwich and the making and eating of that sandwich don't affect anyone other than me and the person I buy it from, there is no externality. But if I buy electricity and the production of that electricity creates pollution that affects people other than me and the firm selling electricity, that pollution damage is an externality. Because electricity use involves costs that neither the buyer nor seller bear, inefficiently too much electricity will be used in a free market- the world would be better off if less electricity was used.

Externalities show up in public goods problems. A public good is a good that is non-rival (one person's "use" of the good does not decrease the value someone else gets from using it) and nonexcludable (it is impossible or very costly to stop someone, including yourself, from consuming the good). Pollution is effectively non-rival and non-excludable: my neighbor's exposure to particulate pollution does not diminish the particulate pollution to which I am exposed, and I am exposed to the pollution without opting into it and I am not able to opt out of it (except at a large cost). Since pollution is undesirable, we call it a public bad (a cost that is non-rival and nonexcludable).

Because public goods and bads involve externalities, these situations result in inefficiency as well. For example, people making decisions to provide public goods do not bear all of the benefits of their decisions; as a result they will provide too little of the public goods. 
Now let us consider land conservation. When we say that land is conserved, we usually mean that it is kept out of some environmentally-intensive land use. Development (building residential or commercial buildings on the land) is obviously intensive as compared to leaving land as greenspace. Agriculture is usually less intensive than development. However, agriculture can have environmental impacts, too. Farming is therefore more intensive than leaving the land in a natural state or actively conserving it (which may involve planting trees or native plants on it, clearing out invasive species, or remediating pollution that has accumulated on the land).

Land conservation provides many public goods-benefits that are non-rival and non-excludable. These benefits are referred to collectively as ecosystem services. Relative to farming, conservation decreases erosion. Erosion causes damage to land by removing soil and to waterways by depositing that soil (and sometimes pesticides and fertilizers along with it) into the water. This can cause water to be too nutrient-rich, which can cause algae to bloom and devour all of the oxygen in the water, thus causing fish and other creatures to die. Conserved land is also often able to filter water, which can protect local areas from flooding and can improve groundwater availability. Conservation may also provide habitat to plant and animal species, and these species may be important ecologically (e.g., they may be key predator or prey species helping maintain balance in other species’ populations) and also culturally to humans (for example, we call large animals that humans care a lot about charismatic megafauna). In some cases, conserved land may provide direct inputs to the production of marketed goods: for example, wild bees pollinate local orchards, and mangrove swamps enable shrimp populations to flourish. Some kinds of conserved land provide other local and global climate benefits: trees reduce temperatures locally and absorb carbon dioxide to abate climate change globally. People may also value having natural land in existence around them, either for recreation purposes or simply because they like to know the land is preserved; these values are also often considered an ecosystem service.

Because these ecosystem service benefits generated by land conservation are public goods, in a free market there is too little land conservation. This is the rationale for creating government policies that encourage land conservation. 


\section{References}

Andelman, Sandy J and Fagan, William F, 2000. "Umbrellas and flagships: efficient conservation surrogates or expensive mistakes?" Proceedings of the National Academy of Sciences, 97(11), 5954-5959.

Ando, Amy, Camm, Jeffrey, Polasky, Stephen and Solow, Andrew, 1998. "Species distributions, land values, and efficient conservation." Science, 279(5359), 2126-2128.

Ando, Amy W and Mallory, Mindy L, 2012. "Optimal portfolio design to reduce climate-related conservation uncertainty in the Prairie Pothole Region." Proceedings of the National Academy of Sciences, 109(17), 6484-6489.

Andreoni, James, 1989. "Giving with impure altruism: Applications to charity and Ricardian equivalence." The Journal of Political Economy, 97(6), 1447.

Chouinard, Hayley H., Paterson, Tobias, Wandschneider, Philip R. and Ohler, Adrienne M., 2008. "Will Farmers Trade Profits for Stewardship? Heterogeneous Motivations for Farm Practice Selection." Land Economics, 84(1), 66-82.

Clucas, Barbara, McHugh, Katherine and Caro, Tim, 2008. "Flagship species on covers of US conservation and nature magazines." Biodiversity and Conservation, 17(6), 1517-1528.

Conrad, Jon M, Gomes, Carla P, van Hoeve, Willem-Jan, Sabharwal, Ashish and Suter, Jordan F, 2012. "Wildlife corridors as a connected subgraph problem." Journal of Environmental Economics and Management, 63(1), 1-18.

Dissanayake, Sahan TM, Önal, Hayri, Westervelt, James D and Balbach, Harold E, 2012. "Incorporating species relocation in reserve design models: An example from Ft. Benning GA." Ecological Modelling, 224(1), 65-75.

Dobson, Andrew P, Rodriguez, Jon P, Roberts, W Mark and Wilcove, David S, 1997. "Geographic distribution of endangered species in the United States." Science, 275(5299), 550-553.

Feather, Peter, Hellerstein, Daniel and Hansen, Leroy, 1999. "Economic Valuation of Environmental Benefits and the Targeting of Conservation Programs: The Case of the CRP." United States Department of Agriculture Economic Research Service Report \#778, Washington, DC, USA.

Haddad, Nick M, Brudvig, Lars A, Clobert, Jean, Davies, Kendi F, Gonzalez, Andrew et al., 2015. "Habitat fragmentation and its lasting impact on Earth’s ecosystems." Science Advances, 1(2), e1500052.

Holt, Charles A., 1999. "Teaching Economics with Classroom Experiments: A Symposium." Southern Economic Journal, 65(3), 603-610.

Jacobson, Sarah, 2014. "Temporal spillovers in land conservation." Journal of Economic Behavior \& Organization, 107, Part A(0), 366-379.

Messer, Kent Donald, 2006. "The conservation benefits of cost-effective land acquisition: a case study in Maryland." Journal of Environmental Management, 79(3), 305-315.

Millennium Ecosystem Assessment, 2005, Millennium Ecosystem Assessment General Synthesis Report: Ecosystems and Human Well-being. Millennium Ecosystem Assessment.

Önal, Hayri and Briers, Robert A, 2006. "Optimal selection of a connected reserve network." Operations Research, 54(2), 379-388.

Parkhurst, Gregory M and Shogren, Jason F, 2007. "Spatial incentives to coordinate contiguous habitat." Ecological Economics, 64(2), 344-355. 
Polasky, Stephen, Lewis, David J, Plantinga, Andrew J and Nelson, Erik, 2014. "Implementing the optimal provision of ecosystem services." Proceedings of the National Academy of Sciences, 111(17), 6248-6253.

Polasky, Stephen, Nelson, Erik, Camm, Jeff, Csuti, Blair, Fackler, Paul et al., 2008. "Where to put things? Spatial land management to sustain biodiversity and economic returns." Biological conservation, 141(6), 1505-1524.

Pressey, Robert L, Cabeza, Mar, Watts, Matthew E, Cowling, Richard M and Wilson, Kerrie A, 2007. "Conservation planning in a changing world." Trends in ecology \& evolution, 22(11), 583-592.

Preston, Frank W, 1962. "The canonical distribution of commonness and rarity: Part I." Ecology, 43(2), 185-215.

Sukhdev, Pavan, Wittmer, Heidi, Schröter-Schlaack, Christoph, Nesshöver, Carsten, Bishop, Joshua et al., 2010, The economics of ecosystems and biodiversity: mainstreaming the economics of nature: a synthesis of the approach, conclusions and recommendations of TEEB. TEEB.

Sullivan, Patrick, Hellerstein, Daniel, Hansen, LeRoy, Johansson, Robert, Koenig, Steven et al., 2004. "The Conservation Reserve Program: Economic Implications for Rural America." United States Department of Agriculture Economic Research Service, Washington, DC.

The Economist, 2008, "Branding Land." 